\title{
Epopée et mémoire nationale au XVII siècle. Actes du colloque tenu à l'Université de Caen réunis par F. Wild
}

\section{Monica Pavesio}

\section{(2) OpenEdition}

1 Journals

\section{Edizione digitale}

URL: https://journals.openedition.org/studifrancesi/3077

DOI: 10.4000/studifrancesi.3077

ISSN: 2421-5856

\section{Editore}

Rosenberg \& Sellier

\section{Edizione cartacea}

Data di pubblicazione: 1 juillet 2013

Paginazione: 452

ISSN: 0039-2944

\section{Notizia bibliografica digitale}

Monica Pavesio, «Epopée et mémoire nationale au xvı" siècle. Actes du colloque tenu à l'Université de Caen réunis par F. Wild», Studi Francesi [Online], 170 (LVII | II) | 2013, online dal 30 novembre 2015, consultato il 02 février 2023. URL: http://journals.openedition.org/studifrancesi/3077 ; DOI: https:// doi.org/10.4000/studifrancesi.3077

Questo documento è stato generato automaticamente il 2 février 2023.

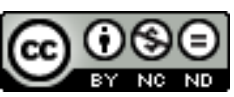

Creative Commons - Attribuzione - Non commerciale - Non opere derivate 4.0 Internazionale - CC BYNC-ND 4.0

https://creativecommons.org/licenses/by-nc-nd/4.0/ 


\title{
Epopée et mémoire nationale au XVII siècle. Actes du colloque tenu à l'Université de Caen réunis par F. Wild
}

\author{
Monica Pavesio
}

\section{NOTIZIA}

Epopée et mémoire nationale au XVII ${ }^{\mathrm{e}}$ siècle. Actes du colloque tenu à l'Université de Caen (12-13 mars 2009), réunis par F. WILD, Caen, Presses Universitaires de Caen, 2011, pp. 226.

1 Nel XVII secolo, quando la Francia inizia ad avere un ruolo dominante in Europa, a livello militare, politico e culturale, emerge la necessità di celebrare la nazione francese, creando degli eroi nazionali. Personaggi che devono appartenere alla stirpe dei re ed avere abbracciato la religione cristiana, come Clodoveo, Carlomagno e San Luigi. È in questo periodo, dunque, che si sviluppa il genere dell'epopea nazionale.

2 Le comunicazioni riunite nel volume curato da F. Wild mettono in evidenza i legami delle epopee secentesche con la tradizione epica precedente e con l'attualità politica contemporanea.

3 La prima sezione intitolata «Contextes» contiene quattro comunicazioni. J. M. CONSTANT, specialista d'antropologia storica, nel suo articolo Littérature et construction politique: le héros de la Ligue à la Fronde, studia la perdita di valore dell'eroismo virile, alla base della scrittura epica, in una società ormai governata da un potere centrale forte, e si sofferma sulla popolarità verso la metà del secolo di valori femminili e di personaggi, come Gaston d'Orléans, che rappresentano l'antieroismo. In Amazones et guerrières: esquisse d'une épopée future chez Marie de Gournay, G. DEVINCENzo riprende le tematiche dell'eroismo femminile nell'opera di Marie de Gournay, appassionata amazzone ed ammiratrice di Giovanna d'Arco. A Mazarino, al suo interesse per l'epopea, ed alla 
celebrazione della sua gloria, (Mazarin mécène de l'épopée) è dedicato l'articolo di Y. Loskoutoff, mentre M. G. LALLEMAND (La Calprenède et l'épopée) si occupa del Faramond, l'epopea di La Calprenède, scritta in prosa come un romanzo, e dedicata al nuovo re Luigi XIV. L'opera di La Calprenède segna la fine dell'epopea in versi e l'inizio dell'egemonia del romanzo.

La seconda sezione, «Ecriture», contiene una serie di articoli che rintracciano i modelli antichi nelle epopee moderne: D. BJAïs analizza il Clovis di Desmaret, avvicinandolo all'epopea rinascimentale ("Vois-tu Clovis grand honneur des Troyens?": images du premier roi chrétien dans l'épopée de la Renaissance); F. WiLD ritraccia la narrazione epica sempre nel Clovis e ne La Pucelle (La narration épique dans La Pucelle (1656) et dans Clovis (1657); ancora nel Clovis di Desmarets, M. RoussiLlon ritrova la presenza di motivi direttamente ripresi dai romanzi di cavalleria (Usages du merveilleux dans le "Clovis" de Desmarets de Saint-Sorlin). All'Alaric di Scudéry è dedicato l'articolo di Ph. СномÉTY, Du poème épique à la poésie d'idées: philosophie, science et morale dans "Alaric, ou Rome vaincue" (1654) de Georges de Scudéry. Torniamo poi sull'epopea femminile con il saggio di N. GRANDE sulla Judith di Marie de Calages (Une figure féminine épique: "Judith" de Marie de Calages), mentre A. MONTERO dedica la sua attenzione alla poetica ed alla politica nel Charle Martel di Carel de Sainte-Garde (Poétique et politique dans le "Charle Martel" de Carel de Sainte-Garde).

5 L'ultima sezione del volume è dedicata allo studio delle poetiche del genere. G. GIORGI (Epopée et roman dans les poétiques italiennes et françaises du genre narratif aux $\mathrm{XVI}^{e}$ et XVII siècle) sintetizza i dibattiti, prima italiani e poi francesi, che hanno preceduto la nascita dell'epopea secentesca in Francia, e si sofferma sulla forte influenza del Tasso; J. F. CASTILLE rintraccia il verso eroico e ne analizza la poetica nel Clovis di Desmarets ( «Le héros et le vers ne composent qu'un corps»: la poétique du vers héroïque dans le "Clovis" de Desmarets de Saint Sorlin); P. THOUVENIN illustra l'importanza delle poetiche gesuitiche nella riflessione sull'epopea (Une poétique épique jésuite? Les traités des Pères Mambrun, Le Moyne et Rapin dans le classicisme français).

Una ricca bibliografia, un indice dei nomi e delle opere, un breve riassunto in francese ed in inglese degli articoli, una nota biografica sugli autori concludono il volume. 